\title{
Positioning of Customer Order Decoupling Point in the Internet
}

\author{
Environment \\ Qiuxia Hou , Juxiang Wang * \\ Qingdao University, China \\ *Corresponding author: Juxiang Wang, professor, 0532-85953173, jxwang99@163.com
}

\begin{abstract}
The paper constructs a supply chain model which is composed of the generic module supplier and the manufacturer when implementing mass customization in the internet environment. Also, the paper gives the mass customization supply chain delay production cost optimization model, considering intelligent cost caused by adding intelligent modules. In the end, the paper determines the optimal CODP location by using numerical simulation. The simulation shows that, the CODP location moves downstream after adding intelligence modules and thus more modules need to be generalized for achieving intelligence, which can also shorten response time and improve customer satisfaction.
\end{abstract}

Keywords: customer order decoupling point; mass customization; internet+; postponement; queuing theory

\section{Introduction}

Through combining the advantages of mass production and customization, perfectly achieves the goal of low cost and satisfying customer demand, mass customization becomes production pattern of many manufacturing enterprises. Postponement is a very important strategy applied in implementing mass customization, and a core problem of implementing the strategy is positioning the customer order decoupling point (CODP). The coming of "internet+", making mass customization implemented by more manufacturing enterprises possible, and enterprises should determine appropriate CODP position facing intelligence of production process and products to achieve the goal of meeting customer personalized demand with low cost and quick response time.

The aim of the paper is to determine an appropriate CODP position in the environment of "internet+", and provide some implications for the firms implementing mass customization.

The paper is organized as follows: Section 2 reviews literature related to CODP position. Section 3 constructs the model of mass customization in the environment of internet. Section 4 describes the delayed production cost optimization basic model after adding intelligence modules. Section 5 develops the model using queuing theory. Section 6 obtains results through MATLAB software simulation. Section 7 summarizes and achieves conclusions. 


\section{Literature}

Many scholars in history mainly research on the position of CODP standing on two angles, one is process angle, Lee and Tang $(1997)^{1}$ constructed a quantitative model on CODP position towards manufacturing delay aiming for the lowest total cost, and assessed three postponement strategies of standardization of components, modular design and process reengineering using the model. Xiaofeng Shao $(2002)^{2}$ constructed single and multiple CODP position models with the goal of lowest total cost, and compared the inventory costs of centralized and decentralized decision-making in his doctoral thesis. Zhiqiang Fan ${ }^{3}$ improved the model in the relevant parameter settings and time constraint conditions on the basis of Lee and Tang and Xiaofeng Shao, constructed total cost model of CODP position respectively towards logistics delay and manufacturing delay. Zhihua Wu, Jianqiang Luo et al. ${ }^{4}$ proved that adding service module in CODP downstream will increase total cost of original production system and extend customer waiting time, but moving CODP upstream through outsourcing and refining CODP upstream business will increase profit margins. The other is manufacturing time angle, Kai Rao, Bin Dan et al. ${ }^{5}$ constructed manufacture postponement production total cost optimization model, extended the model with $\mathrm{M} / \mathrm{M} / 1$ queuing system, and made sensitivity analysis to parameters which affect CODP position, and determined the optimal location of CODP through numerical simulation. Dandan $\mathrm{Li}^{6}$ went a step further standing on the supply chain angle, positioned CODP through establishing a two-level supply chain total cost model composed of manufacturer and retailer. Wenhui Zhou, Renqian Zhang et al. ${ }^{7}$ measured supply chain performance with inventory level and customer order unfill rate, established form postponement total cost optimization model composed of semi-finished inventory holding cost and penalty cost for tardiness, and found an efficient algorithm to confirm the optimal location of CODP and inventory level. The paper researches on the manufacturing time angle. First, we construct a two-level supply chain composed of the generic module supplier and the manufacturer. Then we establish a supply chain total cost optimal model in the internet environment, and extend the model with M/M/1 queuing theory. Last, we determine the optimal CODP position through numeric simulation, and prove that CODP moves downstream after adding intelligence module, hence, enterprises should use more generic modules which can also shorten lead time and improve customer satisfaction.

\section{Mass customization model in the internet environment}

In the internet environment, customer can realize zero distance communication with manufacturer and supplier, so does manufacturer and supplier. At this time, supplier is no longer a simple parts supplier, but a generic module supplier. Customer orders can arrive at the plant directly. Generic module supplier designs generic modules through user interaction platform before receiving customer orders, predicts customer demand with big data after confirming optimal design, then produces generic modules according to prediction, generic semi-finished products produced become buffer stock. This process is make-to-stock (MTS). 
After receiving customer orders, manufacturer designs products according to specific customer demand, and confirms optimal design which obtains customer satisfaction through internet interaction, then produces personalized products belonging to different customers, every personalized module will be marked and carry information of its customer in order to identify and assemble, and adds customized intelligence modules in the personalized production process. Finally, the plant contacts customers and delivers products to customers directly. This process is make-to-order (MTO). The whole process can be described as Fig. 1.

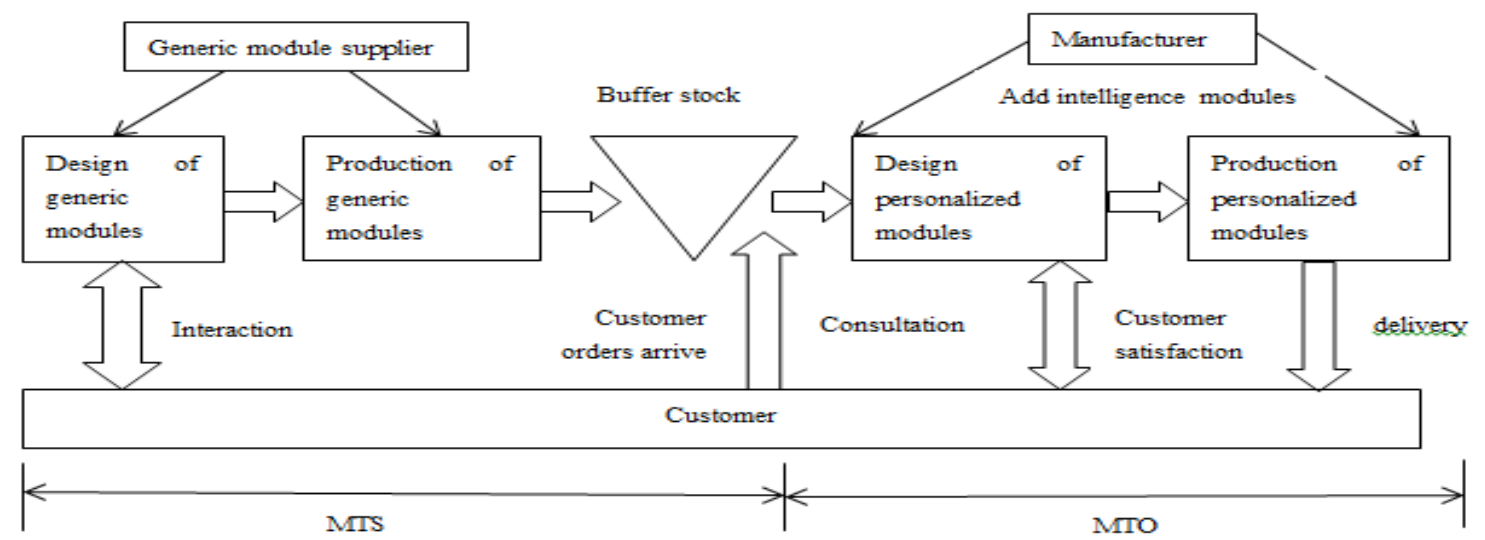

Fig. 1 -Mass customization model in the internet environment

\section{A postponement production cost optimization basic model after adding intelligence modules}

\subsection{Assumptions}

(1)We consider a supply chain composed of a generic module supplier and a manufacturer. In the supply chain, generic semi-finished products enter buffer stock when produced and hold by supplier, and final products when produced will be delivered to the customer immediately. In other words, manufacturer implements zero inventory strategy, thus inventory cost of finished products doesn't exist. And time postponement which generic semi-finished products transport from generic module supplier to manufacturer is not be taken into consideration.

(2)Personalized orders of customers will arrive at the plant directly. We research products belonging to a same product family, and assume that the variety of personalized products is $\mathrm{N}$. For the personalized product of $\mathrm{i}$ in the product family, the customer demand is a stochastic variable which mean is $\lambda_{2, \mathrm{i}}$ and variance is $\sigma_{2, \mathrm{i}}{ }^{2}$, thus, the total demand of all customized products in the product family is: $\mathrm{D}=\sum_{\mathrm{i}=1}^{N} \lambda_{2, \mathrm{i}}$.

(3)The total production time of every kind of customized product is T, manufacturing process can be divided two stages, the first is generic module supplier produce generic modules according to prediction (MTS), the second is manufacturer produce personalized products according to customer orders (MTO), the separation point of the two stages is customer order decoupling point (CODP). We use $r(0 \leq r \leq 1)$ which represents the ratio of generic modules production time to the total production time to position customer order decoupling point. 
(4)Material suppliers can provide materials and parts timely, thus there are not shortage cost.

(5)Customized products manufacturer produced will be delivered to customers immediately, the strategies implemented by manufacturer include form postponement and time postponement, location postponement is not taken into consideration.

(6)We don’t consider customer return cost caused by quality problems.

\subsection{A CODP position basic model}

On researching CODP position in the internet environment, we need to optimize the total cost. We consider the two-stage supply chain composed of generic module supplier and manufacturer, so we need to optimize the total cost of the supply chain Z(r). To position CODP, we need to analyse factors which influence CODP position when supply chain implements postponement strategy. According to related research, CODP position will influence the total cost of generic module supplier $\mathrm{Cs}(\mathrm{r})$ and manufacturer $\mathrm{Cm}(\mathrm{r})$. And the total cost of generic module supplier $\mathrm{Cs}(\mathrm{r})$ includes manufacturing cost $\mathrm{C}_{\mathrm{M} 1}(\mathrm{r})$, holding cost of work-in-process products $\mathrm{C}_{\mathrm{H} 1}(\mathrm{r})$, inventory cost of semi-finished products $\mathrm{C}_{\mathrm{k}}(\mathrm{r})$, investment cost $\mathrm{F}(\mathrm{r})$ and customer waiting cost $\mathrm{C}_{\mathrm{d}}(\mathrm{r})$. And the total cost of manufacturer $\mathrm{Cm}(\mathrm{r})$ includes manufacturing cost $\mathrm{C}_{\mathrm{M} 2}(\mathrm{r})$, holding cost of work-in-process products $\mathrm{C}_{\mathrm{H} 2}(\mathrm{r})$, purchase cost $C_{j}(r)$, and penalty cost due to delayed delivery $C_{p}(r)$. In the internet environment, manufacturer adds intelligence modules in the personalized production stage, thus intelligence cost $\mathrm{C}_{\mathrm{y}}(\mathrm{r})$ should be taken into consideration. The total production cost of supply chain optimization model can be described as follows:

$\operatorname{MinZ}(r)=\operatorname{Cs}(r)+\operatorname{Cm}(r)$

$\operatorname{MinZ}(r)=C_{M 1}(r)+C_{M 2}(r)+C_{H 1}(r)+C_{H 2}(r)+C_{s}(r)+F(r)+C_{d}(r)+C_{j}(r)+C_{P}(r)+C_{y}(r)$

\begin{tabular}{|c|c|}
\hline Notations & Definition \\
\hline$a_{1}(r)$ & The unit average manufacturing cost for generic module supplier \\
\hline$a_{2, i}(r)$ & The unit average manufacturing cost of customized product $i$ for manufacturer \\
\hline $\mathbf{h}_{1}(\mathrm{r})$ & The average holding cost of work-in-process products per unit time for supplier \\
\hline $\mathbf{h}_{2, \mathrm{i}}(\mathrm{r})$ & $\begin{array}{l}\text { The average holding cost of work-in-process products per unit time to customized product } \\
\text { i for manufacturer }\end{array}$ \\
\hline$\rho_{1}(r)$ & The production time of work-in-process products for generic module supplier \\
\hline$\rho_{2, i}(r)$ & $\begin{array}{l}\text { The production time of work-in-process products to customized product i for } \\
\text { manufacturer }\end{array}$ \\
\hline$s(r)$ & The unit average inventory cost of semi-finished products for generic module supplier \\
\hline $\mathrm{E}[\mathrm{I}](\mathrm{r})$ & The expected volume of inventory of semi-finished products for generic module supplier \\
\hline $\mathbf{d}_{2, i}$ & The unit customer waiting cost to customized product i for generic module supplier \\
\hline $\mathrm{ET}_{2, \mathrm{i}}(\mathrm{r})$ & The expected waiting time to customized product i for generic module supplier \\
\hline $\mathbf{J}_{\mathrm{i}}(\mathrm{r})$ & The unit purchase cost to customized product i for manufacturer \\
\hline$p$ & The penalty cost per unit customer waiting time for manufacturer \\
\hline$W_{q}$ & The customer waiting time for manufacturer \\
\hline $\mathrm{y}_{i}(\mathrm{r})$ & The unit intelligence cost to customized product i for manufacturer \\
\hline
\end{tabular}

Fig. 2 -Notations and definition

When $r$ is CODP position, we can unfold the model as follows. And notations are defined in Fig. 2.

$$
\operatorname{Cs}(\mathrm{r})=\sum_{i=1}^{N} \lambda_{2, i} a_{1}(r)+h_{1}(r) \rho_{1}(r)+s(r) E[I](r)+F(r)+\sum_{i=1}^{N} d_{2, i} \lambda_{2, i} E T_{2, i}(r)
$$




$$
\begin{gathered}
\operatorname{Cm}(r)=\sum_{i=1}^{N} \lambda_{2, i} a_{2, i}(r)+\sum_{i=1}^{N} h_{2, i}(r) \rho_{2, i}(r)+\sum_{i=1}^{N} J_{i}(r) \lambda_{2, i}+p W_{q}+\sum_{i=1}^{N} \lambda_{2, i} y_{i}(r) \\
\operatorname{MinZ}(r)=\sum_{i=1}^{N} \lambda_{2, i} a_{1}(r)+\sum_{i=1}^{N} \lambda_{2, i} a_{2, i}(r)+h_{1}(r) \rho_{1}(r)+\sum_{i=1}^{N} h_{2, i}(r) \rho_{2, i}(r)+s(r) E[](r)+F(r)+\sum_{i=1}^{N} d_{2, i} \lambda_{2, i} E T_{2, i}(r)+\sum_{i=1}^{N} J_{i}(r) \lambda_{2, i}+p W_{q}+\sum_{i=1}^{N} \lambda_{2, i} y_{i}(r) \\
\left\{\begin{array}{l}
0 \leq r \leq 1 \\
0<\lambda_{2, i} / \mu_{2, i}<1 \quad(0<\mathrm{DT}<1)
\end{array}\right.
\end{gathered}
$$

The Eq. (3) denotes the total cost of generic module supplier, the Eq. (4) denotes the total cost of manufacturer, the Eq. (5) denotes the total cost of supply chain optimization model, and the restriction $0<\lambda_{2, i} / \mu_{2, i}<1$ denotes that productivity is more than the arrival rate of customer orders in the personalized products production stage for manufacturer. Thus, customer orders can be handled timely.

\section{A postponement production cost optimization extending model after adding intelligence modules}

The modules demand of manufacturer and the arrival of customer order can be regarded as Poisson stream so that basically meet the ordinary, stationary, independence characteristics. We assume that manufacturer produces customized products following the rule of first come first service, so the postponement production system can be regarded as two $M / M / 1$ queuing systems. On researching CODP position from manufacturing time angle in the internet environment, in order to simplify our research, we make further assumptions as follows:

(1)Because $\mathrm{N}$ varieties of customized products belong to the same product family, customized attributes of products are basically identical, we assume that customized parameters of $\mathrm{N}$ kinds of customized products are identical, that is to say, $\lambda_{2, i}, \mu_{2, i}, a_{2, i}, \rho_{2, i}, h_{2, i}, \sigma_{2, i}$, $d_{2, i}, \mathrm{ET}_{2, \mathrm{i}}, \lambda_{i}, J_{i}, y_{i}$ can be simplified as: $\lambda_{2}, \mu_{2}, a_{2}, \rho_{2}, h_{2}, \sigma, d, \mathrm{ET}_{2}, \lambda, J$, $y$.

(2)With CODP position moving downstream, more modules of products need to be standardized, we need to improve production process constantly, so R \& D cost will increase constantly and flexibility requirements of generic semi-finished products manufacturing center will be even higher. Thus, CODP position moving downstream will cause an increase of investment cost including R \& D of production process and investment of fixed equipment. Therefore, we assume that $\mathrm{F}(\mathrm{r})$ is a linear increasing function about $\mathrm{r}$.

(3)If value adding of customized products production over time is a homogeneous and continuous process, we assume that $\mathrm{a} 1(\mathrm{r})$ and $\mathrm{s}(\mathrm{r})$ are all linear increasing functions about $\mathrm{r}$, and $\mathrm{a} 2(\mathrm{r})$ is a linear decreasing function about $\mathrm{r}$.

(4)Value of products is increasing during manufacturing over time, so $\mathrm{h}_{1}$ (r) $<\mathrm{s}$ (r) $<\mathrm{h}_{2}$ (r).

(5)In the internet environment, intelligence modules are added at the stage of customized 
products production. The complexity of intelligence modules and the complexity caused by intelligence of production process will directly lead to increased production time, so the length of production time will directly determine intelligence cost level. With CODP position moving downstream, intelligence production time will be shorter, and unit intelligence cost will be reduced. Thus, we assume that intelligence cost for per unit of product is a linear decreasing function about $r$.

According to the research of BUZACOTT ${ }^{8}$, the efficiency indicators of poisson distribution are very similar to normal distribution when the amount of customer demand is relatively large, so we use normal distribution to replace poisson distribution approximately, efficiency indicators obtained as follows:

Production intensity of supplier: $\rho_{1}=\lambda_{1} / \mu_{1}=\mathrm{rDT}$

Production intensity of manufacturer: $\rho_{2}=\lambda_{2} / \mu_{2}=(1-\mathrm{r}) \mathrm{DT}$

Expected production time of generic modules: $E T_{1}=1 /\left(\mu_{1}-\lambda_{1}\right)=1 /(1 / \mathrm{rT}-\mathrm{D})$

Expected production time of customized products:

$$
E T_{2}=1 /\left(\mu_{2}-\lambda_{2}\right)=N(1-r) T /(1-D T(1-r))
$$

Expected volume of inventory of semi-finished products:

$$
\begin{aligned}
& E[\mathrm{I}](r)=\mathrm{D} / 2+\mathrm{z} \bar{\sigma} \sqrt{r T+1} \\
& \bar{\sigma}^{2}=\sum \sigma_{j}{ }^{2}+\sum_{i \neq j} p_{i j} \sigma_{i} \sigma_{j}
\end{aligned}
$$

In Eq. (10), z denotes a safety factor associated with generic modules. Also, in Eq. (11), $\rho_{\mathrm{ij}}$ denotes a correlation coefficient for customer demand of customized product $i$ and product $j$. So we extend the model as follows:

$$
\begin{aligned}
& \operatorname{MinZ}(\mathrm{r})=\mathrm{D} * a_{1}(r)+\mathrm{D} * a_{2}(r)+\mathrm{r}^{*} \mathrm{D} * \mathrm{~T} * \mathrm{~h}_{1}(\mathrm{r})+\mathrm{h}_{2}(\mathrm{r}) *(1-\mathrm{r}) * \mathrm{~N} * \mathrm{D} * \mathrm{~T}+\mathrm{s}(\mathrm{r})(\mathrm{D} / 2+\mathrm{z} \bar{\sigma} \\
& \sqrt{ }(\mathrm{rT}+1))+\mathrm{D} * \mathrm{~d} /(1 / \mathrm{rT}-\mathrm{D})+\mathrm{F}(\mathrm{r})+\mathrm{D} * \mathrm{~J}(\mathrm{r})+\mathrm{p} * \mathrm{~N}(1-\mathrm{r}) \mathrm{T} /(1-\mathrm{D}(1-\mathrm{r}) * \mathrm{~T})+\mathrm{D} * \mathrm{y}(\mathrm{r}) \\
& \left\{\begin{array}{l}
0 \leq r \leq 1 \\
0<\lambda_{2, i} / \mu_{2, i}<1 \quad(0<\mathrm{DT}<1) \\
h_{1}(r)<s(r)<h_{2}(r)
\end{array}\right.
\end{aligned}
$$

\section{Results of model simulation and analysis}

We assign variables according to the extending model as follows:

$\mathrm{D}=100, \quad a_{1}(r)=0.8 \mathrm{r}, \quad a_{2}(r)=1-\mathrm{r}, \mathrm{h}_{1}(\mathrm{r})=0.6 \mathrm{r}, \mathrm{h}_{2}(\mathrm{r})=2-0.4 \mathrm{r}, \mathrm{N}=10, \mathrm{~s}(\mathrm{r})=0.7 \mathrm{r}, \mathrm{T}=0.009, \mathrm{z}=3$, 
$\bar{\sigma}=0.4, \quad F(r)=50+5 \mathrm{r}, \mathrm{p}=3, \mathrm{~d}=20, \quad J(r)=10-\mathrm{r}, \quad y(r)=3-3 \mathrm{r}$.

We can obtain results as follows through MATLAB software simulation:

(1) The total cost of generic module supplier changes as the CODP position moves in Fig. 3.

As Fig. 3 shows, the total cost of generic modules supplier increases with CODP position moving downstream.

(2) The total cost of manufacturer before and after adding intelligence modules changes as the CODP position moves in Fig. 4.

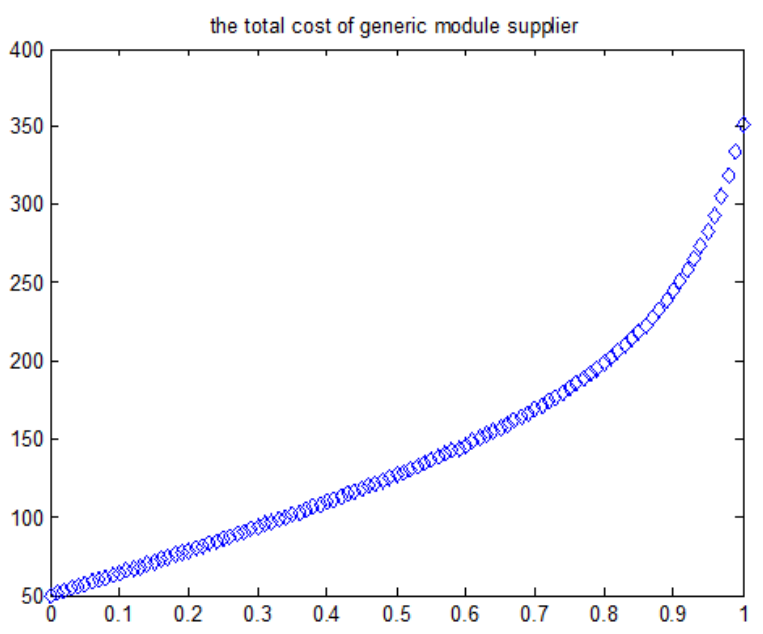

Fig. 3- The influence of CODP position to the total cost of supplier

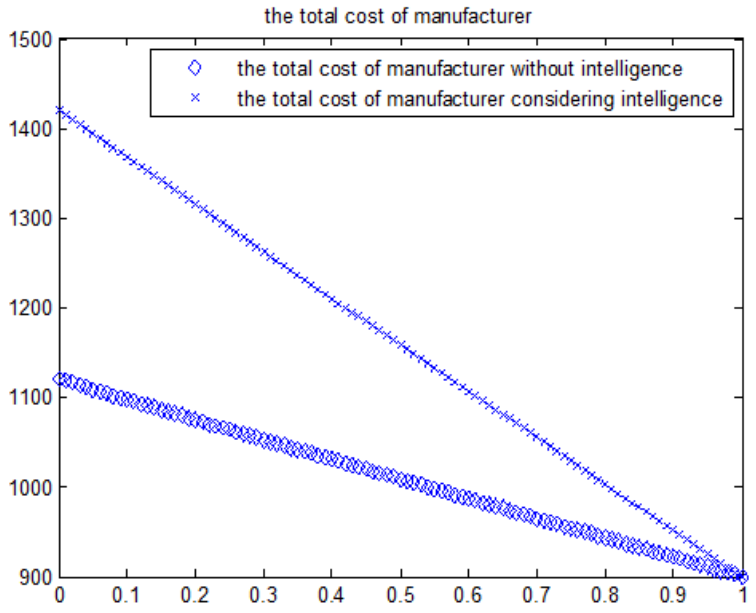

Fig. 4- The influence of CODP position to the total cost of manufacturer before and after adding intelligence

As Fig. 4 shows, the total cost of manufacturer decreases with CODP position moving downstream. After adding intelligence modules, the total cost of manufacturer increases and the increments of total cost decreases with CODP position moving downstream.

(3) The total cost of supply chain before and after adding intelligence modules changes as the CODP position moves in Fig. 5.

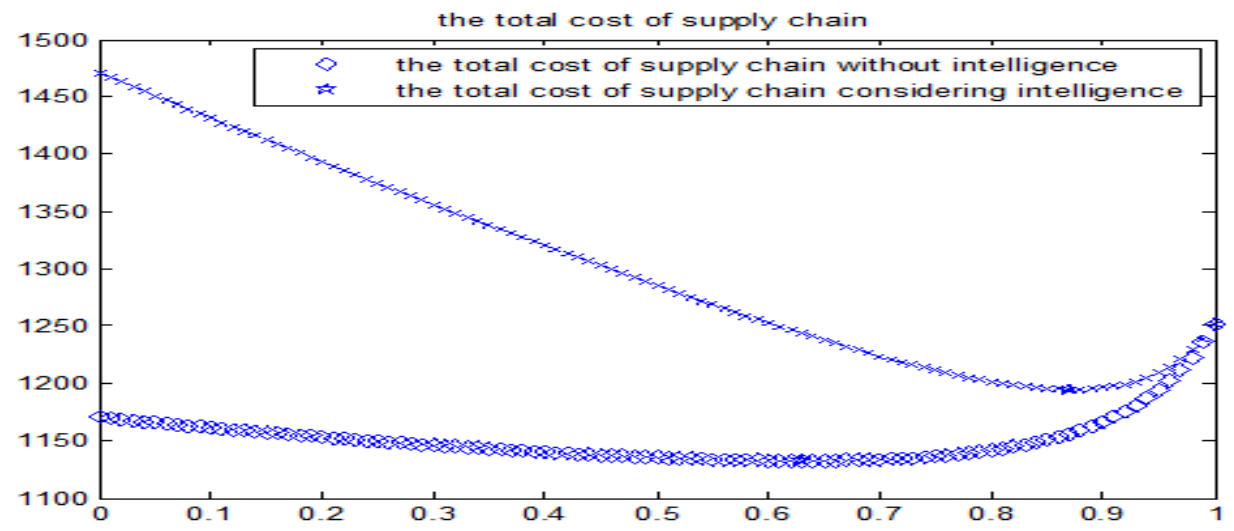

Fig. 5 - The influence of CODP position to the total cost of supply chain before and after adding intelligence

As Fig. 5 shows, the total cost of supply chain decreases initially and increases afterwards with CODP position moving downstream. Before adding intelligence modules, the total cost 
of supply chain attains the lowest level of 1132.5 when $r=0.63$, and the total cost of supply chain attains the lowest level of 1194.7 when $r=0.87$ after adding intelligence modules.

From results of simulation, we can see that after adding intelligence modules, the requirement for standardization is even higher, so enterprises need to make more product modules standardized and universal in order to reduce the total cost of the supply chain.

\section{Conclusion}

In the paper, we construct a mass customization supply chain delay production cost optimization model in the internet environment, and we add intelligence cost caused by adding intelligence modules in the cost optimization model. We determine the optimal position of CODP through numerical simulation. More importantly, we prove that the optimal CODP position moves downstream after adding intelligence modules, so higher requirement in the modular design of products was put forward to for supply chain implementing mass customization, and when the optimal CODP position moves downstream, supply chain will shorten response time to customer order, improve customer satisfaction, cultivate customer loyalty and enhance customer stickiness.

\section{References}

1. H. L. Lee, C. S. Tang, Modeling the Cost and Benefits of Delayed Product Differentiation, J. Management Science. 43 (1997) 40-53.

2. X. S. Shao, Supply chain management facing mass customization, D. Shanghai. Shanghai Jiaotong University. 2002.

3. Z.Q. Fan, Customer order decoupling point position research based on supply chain operation postponement strategy, D. Shanghai. Shanghai Haishi University. 2007.

4. Z.H. Wu, J.Q. Luo, Y.P. Zhao and J.C. Qin, The influence of increasing service modules to implementing postponement production system, J. Industrial Engineering. 16 (2013) 68-73.

5. K. Rao, B. Dan, Y. Liu, Cost optimization model of manufacturer implementation postponement strategy in mass customization, J. Computer Integrated Manufacturing Systems. 9 (2007) 1665-1671.

6. D.D. Li, J.X. Wang, Customer order decoupling point position for mass customization, J. Journal of Qingdao University. 23 (2010) 88-92.

7. W.H. Zhou, R.Q. Zhang et al, A queuing model on supply chain with the form postponement strategy, J. Computers \& Industrial Engineering 66 (2013) 643-652.

8. J.Buzacott, J. G. Shanthikumar, Stochastic models of manufacturing systems. 13, Prentice-Hall, USA, 1993, 145-148. 